\title{
The Experience and Perception of Physiotherapists in Nigeria re: Fall Prevention in Recurrent-Faller Older Adults
}

\author{
Perpetua Chinenye Obi \\ Peak Wellness Centre, Abuja Nigeria., chyobi12@yahoo.com \\ Henrietha Chibuzor Nwankwo \\ Center for Research on Ageing, University of Southampton, Southampton, UK, n.henrietha@gmail.com \\ Diaemeta Emofe \\ Humanity Hospital Limited, Warri Delta State Nigeria, talk2emoefe09@yahoo.com \\ Isreal Adandom \\ Center for Research on Ageing, University of Southampton, Southampton, UK, israeladandom@gmail.com \\ Michael E. Kalu \\ School of Rehabilitation Science, McMaster University, Hamilton Ontario, Canada, kalum@mcmaster.ca
}

Follow this and additional works at: https://nsuworks.nova.edu/ijahsp

Part of the Medicine and Health Sciences Commons

\section{Recommended Citation}

Obi PC, Nwankwo HC, Emofe D, Adandom I, Kalu ME. The Experience and Perception of Physiotherapists in Nigeria re: Fall Prevention in Recurrent-Faller Older Adults. The Internet Journal of Allied Health Sciences and Practice. 2019 Jan 01;17(2), Article 11.

This Manuscript is brought to you for free and open access by the College of Health Care Sciences at NSUWorks. It has been accepted for inclusion in Internet Journal of Allied Health Sciences and Practice by an authorized editor of NSUWorks. For more information, please contact nsuworks@nova.edu. 


\title{
The Experience and Perception of Physiotherapists in Nigeria re: Fall Prevention in Recurrent-Faller Older Adults
}

\begin{abstract}
Background: Effective fall prevention practices are essential for reducing falls among older adults. Rehabilitation professionals like physiotherapists are essential members of the fall prevention team, yet little is known about the experiences of physiotherapists practicing fall prevention in developing nations. Objective: To explore the experiences of physiotherapists in Nigeria who practice fall prevention among older adults. Method: We adopted a phenomenological approach to the traditional qualitative design in this study. We purposefully selected and conducted face-to-face interview with twelve physiotherapists who have treated at least one older adult who reported falling two or three times within last six months. Data was analyzed using thematic analysis. Results: Four themes emerged from our participants: characteristics of recurrent fallers, fall prevention practices, hindrances to fall prevention, and strategies to promote fall prevention practices. In practice, understanding the characteristics (risk factors) of older adults with a history of recurrent falls is important for effective fall prevention practices among physiotherapists. Among other characteristics, our participants believed that older adults who have patronized "traditional bone setters/healer" are at the higher risk of having multiple falls. Conclusion: This study adds to the sparse amount of literature concerning the experience of physiotherapist in fall prevention practices in the developing world. More importantly, the findings of this study will strengthen or stimulate discussion around development of fall prevention strategies specific to the developing world context.
\end{abstract}

\section{Author Bio(s)}

Perpetua C Obi BMR.PT, MSc, is a physiotherapist practicing in Nigeria, focusing more on the geriatric population. She obtained her physiotherapy degree from the University of Nigeria and her MSc. Gerontology degree from the University of Southampton, United Kingdom.

Henrietha C Nwankwo BMR.PT, MSc (s) is currently an MSc. Gerontology student at the University of Southampton and a physiotherapist trained at the University of Nigeria. He is also a licensed physiotherapist in Nigeria.

Diaemeta Emoefe BMR.PT, MSc completed his MSc. Gerontology degree from the University of Southampton, UK and obtained his bachelor's degree( Medical Rehabilitation in Physiotherapy) from the University of Nigeria. He is the head of the physiotherapy unit at the Humanity Hospital Limited, Warri, Delta State Nigeria.

Isreal Adandom BMR.PT, MSc(s), is currently completing his MSc. Gerontology from the University of Southampton, UK and obtained his physiotherapy degree from the University of Nigeria.

Michael E Kalu BMR.PT, MSc, $\mathrm{PhD}(\mathrm{s})$, is a physiotherapist and currently a doctoral student at the School of Rehabilitation Science, McMaster University, Hamilton, ON, Canada.

\section{Acknowledgements}

We want to acknowledge Dr. Athina Vlachantoni, her supervisory role in this MSc project at the University of Southampton. We will also like to acknowledge Commonwealth Scholarship Commission, as this project is a product of an MSc Scholarship. This is also attributed to the collective effort of the members of the Emerging Researchers \& Professionals in Ageing- African Network (ERPAAN). 


\title{
IIVAHSP \\ The Internet Journal of Allied Health Sciences and Practice \\ Dedicated to allied health professional practice and education
}

Vol. 17 No. 2 ISSN 1540-580X

\section{The Experience and Perception of Physiotherapists in Nigeria re: Fall Prevention in Recurrent-Faller Older Adults}

\author{
Perpetua Chinenye Obi ${ }^{1}$ \\ Henrietha Chibuzor Nwanko² \\ Diaemeta Emofe ${ }^{3}$ \\ Israel Adandom² \\ Michael E. Kalu ${ }^{4}$ \\ 1. Peak Wellness Center \\ 2. University of Southampton \\ 3. Humanity Hospital Limited \\ 4. McMaster University
}

Nigeria, United Kingdom, Canada

\begin{abstract}
Background: Effective fall prevention practices are essential for reducing falls among older adults. Rehabilitation professionals like physiotherapists are essential members of the fall prevention team, yet little is known about the experiences of physiotherapists practicing fall prevention in developing nations. Objective: To explore the experiences of physiotherapists in Nigeria who practice fall prevention among older adults. Method: We adopted a phenomenological approach to the traditional qualitative design in this study. We purposefully selected and conducted face-to-face interview with twelve physiotherapists who have treated at least one older adult who reported falling two or three times within last six months. Data was analyzed using thematic analysis. Results: Four themes emerged from our participants: characteristics of recurrent fallers, fall prevention practices, hindrances to fall prevention, and strategies to promote fall prevention practices. In practice, understanding the characteristics (risk factors) of older adults with a history of recurrent falls is important for effective fall prevention practices among physiotherapists. Among other characteristics, our participants believed that older adults who have patronized "traditional bone setters/healer" are at the higher risk of having multiple falls. Conclusion: This study adds to the sparse amount of literature concerning the experience of physiotherapist in fall prevention practices in the developing world. More importantly, the findings of this study will strengthen or stimulate discussion around development of fall prevention strategies specific to the developing world context.
\end{abstract}

Keywords: accidental falls, elderly people, Nigeria, physical therapists, professional practice 


\section{INTRODUCTION}

The aging population has been projected to increase across all regions and nations of the world. In Nigeria, individuals 60 years and above would account for the $6.3 \%$ of the Nigeria population in $2050 .{ }^{1}$ Given this projection, it is likely that there would be a rise in falls and mobility issues among older adults.

Falls are the highest cause of morbidity and mortality among those aged 65 years and above. ${ }^{2}$ It has been demonstrated that about $5 \%$ of falls lead to a fracture and the other $95 \%$ of people who have fallen experience serious psychological problems such as fear of falling. ${ }^{3,4}$ It is established that fear of falling most times leads to increased risk of future falls., ${ }^{3,4}$ Older adults often constrain themselves at home because of fear of falling; as a result of this, older adult lower limb muscle strength is reduced because of non-use, which may contribute to falls in the future.

Recurrent falling provides the strongest predictor for future falls in community-dwelling older adults. ${ }^{5}$ Furthermore, fear of falling, muscle imbalance, postural instability, gait abnormality, environmental factors, pain, and cognitive impairment are some of the identified factors for recurrent falls. ${ }^{3,4}$ It is anticipated that most recurrent fallers would visit physicians and physiotherapists either because of pain or to receive prescribed exercises. However, most fallers who have no obvious adverse effects (such as fractures) from falling often do not visit the hospital. ${ }^{6}$ The practice of older adults reporting to the hospital after a fall is more prevalent in developed countries because of the established programs and clinical guidelines that target fall prevention and management. ${ }^{5} \mathrm{In}$ Canada, there are networks of fall prevention teams that adopted the public health approach to fall prevention at all levels of care in several provinces. ${ }^{7}$ Additionally, there are policies and funding that support fall prevention practices. In Australia, for example, there is a program (Australian Medicare Enhanced Primary Care Program) that offers preventive and coordinated care for older Australian with complex care needs focusing more on the multidisciplinary approach to fall prevention. ${ }^{8}$ More than ten years ago, the United State implemented the Falls Free National Plan on falls prevention which focused on fall risk screening and multifactorial strategies utilization. ${ }^{9}$ While there is only one fall prevention strategy in the Sub-Saharan Region- South African Fall Prevention Strategy, there is no published evidence that this strategy has been translated into the clinical setting within the south African context, let alone other African countries. ${ }^{10}$

Fall prevention practices are often multidisciplinary, including geriatricians, physiotherapists, occupational therapists and other allied health care professionals. ${ }^{2}$ Exercises targeted to improve balance and strengthen key muscles are one of the best single

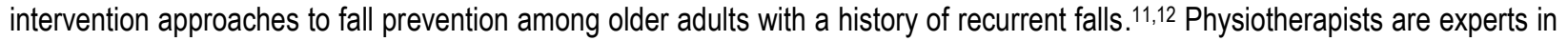
fall prevention among recurrent fallers, prescribing exercises in addition to patient education and home/work modification. There are studies that have explored the level of knowledge and practice level of fall prevention among healthcare workers. Peel et al surveyed physiotherapist in the United State about their level of fall prevention knowledge and practice in a home setting, and Brown et al explored the changes in physical therapist's provider use of fall prevention practices following a multi-component behavioral change intervention. ${ }^{13,14}$ Also, Stenberg \& Wann-Hansson ${ }^{15}$ surveyed healthcare professionals' attitudes and their compliance with clinical practice guidelines to prevent falls and fall injuries. All these studies reported a high level of knowledge and practice of fall prevention among healthcare professionals.

Qualitatively, Middlebrooks and Mackenzie used a grounded theory approach to explore the perceptions of occupational and physical therapists in a fall prevention practice in a primary care program. ${ }^{8}$ They developed a conceptual framework that identifies effective communication and collaboration between the interdisciplinary team and the older adults as a key element in delivering fall prevention programs. Despite the communication issued identified, the participants express the potential benefits of community fall prevention for the older adults including an alternative to being on a waiting list for public health fall prevention. Similar to the developing world context, Middlebrooks and Mackenzie's study highlighted administrative and organizational challenges in implementing the fall prevention program, such as a lack of knowledge about the fall prevention program by general practitioners in private settings. All these studies were done in developed countries.

However, recently, a quantitative study, which seems to be the only study in the sub-Saharan region of Africa, was conducted among physiotherapists in Nigeria to determine their level of knowledge and practice about prevention falls among older adults. ${ }^{16}$ The findings of Kalu et al were relatively consistent with the findings from the studies in other parts of the world; however, there was a great concern about some of the findings. ${ }^{16}$ For instance, the study reported a high level of knowledge and practice among physiotherapists practicing in Nigeria about fall prevention in the older adult; however, over $80 \%$ of the surveyed physiotherapist stated that they have not heard and/or used WHO or any other fall prevention frameworks or strategies. These conflicting findings become a great concern because understanding the conceptual framework informing a practice often results in effective rehabilitation outcomes, in this case, fall prevention outcomes. ${ }^{17}$ Furthermore, it is likely that these conflicting findings of Kalu et al may have been influenced by the data collection tools. ${ }^{16}$ Aside from all these concerns, there is a growing interest in developing fall prevention strategies specific to the Nigerian context. We decided to explore the reasons why many Nigerian physical therapists 
possess a high level of knowledge and practice about fall prevention, but at the same time, are not familiar with existing fall prevention frameworks. We believe that exploring the perception of physiotherapists in Nigeria regarding fall prevention practices among older adults with a history of recurrent falls will further provide contextual evidence to confirm or dispute the findings of Kalu et al, knowing that the training of physiotherapists using conceptual frameworks is evolving in Nigerian physiotherapy training programs. ${ }^{16}$ We also believe that this methodology would be necessary to understand the specific area that needs attention when developing and implementing fall prevention strategies in Nigeria or other countries with similar practice settings. Therefore, this qualitative study aims to explore the perceptions of physiotherapists in Nigeria who do use strategies to reduce recurrent falls in older adults with a history of falling.

\section{METHODS}

We employed a qualitative, description approach to the traditional qualitative to explore the perception of physiotherapists in Nigeria who use strategies to reduce recurrent falls in older adults with a history of fall. ${ }^{18}$ Ethical approval was obtained from the Ethics for Research Governance Committee at the University of Southampton, UK.

\section{Sampling/Recruitment}

Purpose sampling is a general approach to sampling in a qualitative inquiry that aims to identify participants who share the same experience of a central phenomenon of study. ${ }^{19}$ This sampling procedure allowed us to identify individual participant experiences that would contribute to the shared understanding of physiotherapists in Nigeria who fall prevention intervention for older adults who are recurrent fallers. The call to participate in the study was made through the professional page and at various clinics in Abuja and Kaduna metropolitan areas of Nigeria. Participants were allowed to participate if (a) he/she is currently licensed to practice physiotherapy in Nigeria, (b) have at least 5 years of practice as a physiotherapist, and (c) had treated at least one older adults who reported falling two or more times within last six months. All physiotherapy interns and any physiotherapist whose name did not appear on the 2017 Medical Rehabilitation Therapists Board of Nigeria (MRTB) annual online list of registered physiotherapists were excluded from the study. The MRTB is a federal government agency that regulates physiotherapy and other allied healthcare professions in Nigeria. Twenty-three physiotherapists responded to the call to participate in the study; however, only twelve physiotherapists met the inclusion criteria and were recruited. This sample size $(n=12)$ is within the recommended range for a phenomenological study. ${ }^{19}$

\section{Interview Procedure}

Participants that met the inclusion criteria were invited for an interview. The aim, risks, and benefits of participating, confidentiality, anonymity, and the option to withdraw from the research were explained to the participants. All participants provided informed consent prior to being interviewed. The first two interviews were conducted by the first author (OC) and the last author (MK), who were physiotherapists with over 5 years' experience in fall prevention practice among older adults in Nigeria. Subsequently, the first author conducted the interviews for the remaining participants. We interviewed the participants face-to-face using a semistructured interview developed from existing literature (see box below). ${ }^{13,16}$ We conducted a pilot interview to determine the approximate time for the interview; however, the data from the pilot study was not included in the analysis. Each of individual interviews was audio-recorded and lasted between 60 minutes to 120 minutes. We kept reflective notes during each individual interview.

\section{PILOT INTERVIEW GUIDE}

1. Can you describe your role in your clinic or hospital including how long you have worked here, practice as a physiotherapist, estimate of number of older adults you seen in the last 6 months because of fall?

2. Can you describe a typical working day in your clinic?

3. Can you please describe your experience with working with older adults who reported or was referred to your clinic because of falls?

Probe: can you provide instances with details on these experiences?

4. Can you describe what you did when older adults report to your clinic because of falls?

Probe: can you provide instances with details on the strategies that you used in treating these older adults when the report or referred because of falls?

Probe: How did you come about these strategies of fall prevention?

5. Can you describe your experience in collaboration with other healthcare team members during fall prevention strategies?

6 . Are there any other thoughts you would like to share as you experience during fall prevention among older adults?

Thank you so much for the time.

(c) The Internet Journal of Allied Health Sciences and Practice, 2019 


\section{Data Analysis}

Thematic analysis approach described by Clarke and Braun was used in the analysis. ${ }^{20}$ In order for us to ensure the credibility of the coding process, we use the data from the pilot interview to conduct a pilot data analysis. Two coders ( $\mathrm{OB}$ and $\mathrm{NH}$ ) independently and inductively generated initial codes with interpretive concepts to underpinning the meaning of the codes. Later, the codes were merged into categories, and overarching themes were generated from the categories. At each stage of the analysis, both coders met and discussed coding consistency to ensure dependability of the study. ${ }^{21}$ Any disagreement in codes between the two coders $(\mathrm{OB}$ and $\mathrm{NH})$ was discussed with the last author (MK). Afterward, the data was uploaded on $\mathrm{NV}^{2} \mathrm{~T}^{\mathrm{TM}} 10$, a computerized qualitative data management software program designed to assist with the analyses of textual data to aid in the groupings of identified themes (see table 1). The interview and data analysis were performed concurrently to ensure that we stopped interviewing if data saturation was reached. Throughout the analytical process, quotes within the themes were independently scrutinized by each of the authors to ensure credibility. We also conducted respondent validation with the members. The reflective notes used during the interview and coding process were used to validate some of the themes generated in this study, thereby enhancing the dependability of this study. ${ }^{21}$

\section{Trustworthiness}

There were several approaches we incorporated to enhance the trustworthiness of this study. First, we made sure that the participants we interviewed must have had the experience of the phenomena under study-fall prevention practice. ${ }^{19}$ Second, we conducted expert review of the interview guide with five clinician-researchers with over 7 years' experience in qualitative research and fall prevention practice both in Nigeria, Canada, and the UK. They provided feedback on the wordings and number of questions. For instance, they provided feedback to ensure that the interview guide contains the coded language that reflected our research methodology -- qualitative description. ${ }^{18}$ Third, we ensured that the credibility of the study is maintained by involving two coders at all stages of the data analysis. Specifically, we provided detailed account of the coding, theme development, and interpretation process of the data analysis. Fourth, we triangulated our data using our reflexive notes during interviews to guide the interpretation of the findings. We conducted member checking to ensure that we captured the participants' perspectives and experiences in fall prevention practices. Our member checking process was done in two stages: during the interview and after the interview. Member checking during the interview has been suggested to be a better approach of allowing the participants to reflect on their thoughts and provide different perspective to the interview process. ${ }^{22}$ During the interview, we paraphrased and summarized the thoughts of the participants and got confirmation from them on a spot. After the interview, we used the weaker version of ongoing member checking throughout the research process. ${ }^{23}$ The participants received typed summaries and initial codes of which they were allowed to make comments and reflect on their previous comment. This approach provides a more in-depth understanding and further develops their idea and thought on fall prevention in their practice. ${ }^{24}$

\section{RESULTS}

We had 24 codes, which was later merged into 15 sub-themes and subsequently into 4 themes (see table 1). From these codes, sub-themes emerged from the interview process of 12 physiotherapists ( 7 female and 5 male), with the age range of $28-42$ years old and 5-12 years of clinical physiotherapy practice experience in Nigeria (see table 2).

Table 1: Themes and subthemes identified in this study

\begin{tabular}{|l|cl|}
\hline THEME & SUBTHEME \\
\hline Characteristics of recurrent fallers & $\cdot$ & Physical characteristics \\
& $\cdot$ & Psychosocial characteristics \\
& $\cdot$ & Comorbidity related characteristics \\
& $\cdot$ & Environmental related characteristics \\
\hline Practices of fall prevention & $\cdot$ & Traditional bone setter's effects \\
& $\cdot$ & Prescribing physical aids \\
& $\cdot$ & Educational advises \\
& $\cdot$ & Exercise prescription \\
& $\cdot$ & Environmental adaptation \\
\hline Hindrances to practice & $\cdot$ & Finance \\
& $\cdot$ & Communication barrier \\
\hline Strategies to enhance effective fall & $\cdot$ & Lack of infrastructures \\
prevention practices & $\cdot$ & Movernment subsidized services \\
& $\cdot$ & Relative's participation during therapy \\
\hline
\end{tabular}

(๑) The Internet Journal of Allied Health Sciences and Practice, 2019 
Table 2 : Demographic characteristics of participants

\begin{tabular}{|c|c|c|c|c|c|}
\hline $\begin{array}{c}\text { Age } \\
\text { (Years) }\end{array}$ & Gender & Facility of practice & Practice care settings & $\begin{array}{l}\text { Years of experience } \\
\text { as a physiotherapist }\end{array}$ & $\begin{array}{l}\text { Number of older adults } \\
\text { treated in the last } 6 \\
\text { months because of falls }\end{array}$ \\
\hline 37 & M & Teaching Hospital & Inpatient-Orthopedic Unit & 10 & 5 \\
\hline 36 & M & General Hospital & Out-patient Orthopedic Unit & 10 & 6 \\
\hline 42 & M & $\begin{array}{l}\text { Teaching Hospital and } \\
\text { Private Clinic }\end{array}$ & Inpatient-Neurology Unit & 10 & 5 \\
\hline 35 & M & General Hospital & Inpatient -Neurology Unit & 10 & 8 \\
\hline 37 & M & General Hospital & Outpatient- Neurology Unit & 9 & 7 \\
\hline 34 & $\mathrm{~F}$ & Private Clinic & Out-patient (General) & 9 & 3 \\
\hline 34 & $\mathrm{~F}$ & General Hospital & General out-patient Unit & 9 & 3 \\
\hline 34 & $\mathrm{~F}$ & Teaching Hospital & Neurology Unit & 7 & 5 \\
\hline 40 & $\mathrm{~F}$ & General Hospital & General out- patient Unit & 12 & 12 \\
\hline 33 & $\mathrm{~F}$ & General Hospital & Outpatient-Neurology Unit & 8 & 5 \\
\hline 28 & $\mathrm{~F}$ & General Hospital & Outpatient-Neurology Unit & 5 & 9 \\
\hline 32 & $\mathrm{~F}$ & Teaching Hospital & Inpatient-orthopedic Unit & 8 & 7 \\
\hline
\end{tabular}

$\mathrm{F}=$ female, $\mathrm{M}=$ male

\section{Theme 1: Characteristics of Recurrent Fallers}

Characteristic components of recurrent fallers mentioned by participants were varied. All the participants mentioned at least one form of physical characteristics (muscle weakness, poor balance, and gait problems) of older adults who are recurrent fallers. Secondly, participants also believe that psychosocial determinants of fall including fear of falling (emphasized), hesitation, depression, and lack of confidence are contributory to recurrent falls among older adults. The below quote cites this:

"...Older adults who are recurrent fallers often have muscle weakness which results to instability. Most have this huge fear of falling and as a result, confine themselves in a place.... leading to weaker muscles, predisposing them to falling....." (PT 1, male, 37years)

All participants acknowledged that older adults who reported to their clinic because of recurrent falls are diagnosed with two or more chronic conditions (comorbidity). Conversely, only one participant reported that older adults whose environments are not age-friendly are prone to fall. Here is a brief of his experience:

"We had a 70 years old stroke patient referred to us. We built his muscle to a level that enabled mobility. Upon discharge, he was rushed back having fallen at home...... assessment, showed that his home was not adapted to suit his condition. Such consequential oversight resulted to a fall...." (PT 5, male, 37 years) 
Finally, the majority of the participants believed that the unregulated practices of traditional bone setters (traditional healers with no formal education on management of musculoskeletal conditions such as fractures) significantly predispose older adults to falls. The participants believe that during the long treatment session with the traditional bone setters, most patients using them often have associated reduce muscle strength and in some cases power because of non-use of the affected part. As a result, such patients are predisposed to falls because of muscle weakness which is associated with balance. One of the participants stated:

"Many of the recurrent fallers that visit my clinic have visited a traditional bone setter at least once. This is because the belief that stroke is an "evil attack" made them to visit this bone setters (traditional healers). Most of these traditional bone setters inherited the profession from their parents- "it is a family gift" as they say. Therefore, most of them do not even have the basic knowledge of muscle or any other structure in the body, so they don't train the patient's muscle after their leg or hands or even the back has been splinted with stick for over 3 months or more in some cases. Of course, this patient come to use with very muscle weakness which makes them more prone to falls." (PT 8, female, 34 years)

\section{Theme 2: Practices of Fall Prevention}

Educational advice, prescribing physical aids, and exercise and environmental adaption were the sub-themes that emerged as fall prevention practice. All participants believed that providing educational advice relating to fall as well as prescribing physical aids for easier mobility are one of the best fall prevention best practices. Although not regularly practiced in the Nigerian context, participants believed that environmental modification by the occupational therapist is an essential component of fall prevention. The participants believed that these practices coupled with exercises aimed at improving strength and maintaining balance in the lower and upper limbs are the best practices for fall prevention among recurrent fallers, as explained by the quote below:

"Prescription and education about mobility device usage, targeting exercise for specific muscle group, as well as examining history of falls and recommending the services of either an ergonomist or occupational therapist for a workplace or home adaptation should be encouraged in all physiotherapy practice setting in Nigeria." (PT 10, female, 33 years)

\section{Theme 3: Hindrance to Fall Prevention Practices}

All participants believed that insufficient resources in form of funds, human power (healthcare professionals), and basic infrastructure like accessible roads, bus terminals, and buses were the major hindrances to fall prevention practice, as explained below:

"It is quite unfortunate that most patients cannot afford some of the services of the specialist when they fall, so most of them don't even seek a physiotherapist or occupational therapist after falling.... Even some of them that can afford these services, they are more prone to another fall because of bad roads and age unfriendly walk ways- for instance, we prescribed one client a wheelchair, but there is no access of ramps in this neighborhood let alone house." (PT 7, female, 34 years)

Ineffective communication between the therapist and either the patients or the relatives emerged as one of the hindrances to fall prevention practices. This ineffective communication was summarized as either due to language barrier or patient's cognitive capacity, as explained below:

"We are really struggling as therapists here because we don't understand some native languages here... so explaining some of these home exercise to the patients or their relative is a difficult task." (PT 2, male, 36years)

\section{Theme 4: Strategies to Enhance Effective Fall Prevention Practices}

Government subsidies services, model of care for a multidisciplinary approach, and relatives' participation during therapy are the strategies participants believe will enhance effective fall prevention practices. Specifically, one of the participants stated below:

"For older adults, the possibility of free or cheaper health services reduces stress (physical, psychological, and financial) and improves their general well-being... also, an avenue that gives older adults access to multidisciplinary health care professionals especially in the rural areas (where majority of them reside) will be hugely beneficial in reducing fall...." (PT 12, female, 32)

The lack of a multidisciplinary approach to fall prevention practice in Nigeria was emphasized as the best approach for effective fall prevention in Nigeria. One specific suggestion included the creation of fall clinics and fall units in the emergency unit with trained experts as the fall prevention team. Education of the fall prevention team members on screening and identification of older adults 
at high risk of falls should be a regular practice in Accident and Emergency and all physiotherapy practice, as stated by one of the participants below:

"We physiotherapist often assume that we assess fall risk, but how many physiotherapists documents this in their care document? This I believe comes from the training pattern. We were taught to access patients at risk of falls especially if they had stroke, but were never educated that fall screening can serve as a prevention practice-l am not sure if this has changed since I have graduated over 12 years ago." (PT 9, female 40)

Another strategy that emerged was relatives' participation during the fall prevention sessions - education, exercise prescription, etc. The participants believed that relatives have a huge role in fall prevention because they will not only act as a reminder to the clients about the prescribed exercises but would also provide the necessary supervision as the patient performs the home exercises. The participants believe that because most of the relatives have full-time careers, it is important that healthcare professionals educate the relatives, send reminders, and if possible, conduct feedback with them to ensure that they understand the exercise and its benefits. One of the participants gave two scenarios to illustrate this:

"I had a 67-year-old woman that has a granddaughter who finished the university but presently takes care of the grandmother. I gave her home exercise for her grandmother, but she didn't understand anything -- because I used lots of jargon (my bad), but she came back and asked me. That was when I realized that [what I gave her] was full of jargon and I corrected it. The grandmother didn't come back to us because of falls for over two years. I had another experience where I prescribed an exercise [and] showed the person the exercise for the grandmother, but the individual forgot the exercise prescription and didn't even do any of the exercise. The grandmother was brought back to us after two weeks... This is a power of education. If we take out time to educate relatives, they will help a lot in preventing future falls." (PT 5 , male, 35 years)

\section{DISCUSSION}

The aim of this study was to explore the perceptions and experiences of physiotherapists in Nigeria in trying to reduce falls among older adults with a history of recurrent falls. These findings complement the findings of Kalu et al and other quantitative literature on falls. ${ }^{16}$ More importantly, these findings expand the current body of knowledge of fall prevention practices in sub-Saharan Africa by providing context to the experience of fall prevention professionals. In this study, the themes that emerged were consistent with the existing literature. For instance, fear of falling, muscle weakness, and coexisting medical conditions (multifactorial etiology) emerged as some characteristics for recurrent fallers; these factors are identified as risk factors for falls across the literature.3,5,25,26

Surprisingly, our participants reported that older adults who visit traditional bone setters often are more likely to fall than those who did not visit traditional bone setters. This finding is specific to the context of the African region, where many patients often use traditional bone setters as an alternative to care because of cost, cultural belief, or lack of accessibility to hospitals. ${ }^{27}$ In Nigeria, people patronized the traditional bone setters because of the belief that diseases have a spiritual component that needs to be addressed with treatment, and it is believed that traditional bone setters can both offer spiritual and physical treatment. ${ }^{28}$ However, this belief could be misleading because there is no established or formal training for traditional bone setters in Nigeria; therefore, there is no certification or scope of practice, and anyone can claim to be a practitioner. ${ }^{27,28}$

Many of the bone setter practitioners have reported that they acquire their skill through supernatural powers, while a few acquire their skills through apprenticeship or virtually by the fact that their grandparents were traditional bone setters. ${ }^{27}$ Traditional bone setters often treat their client based on their intuition using one major technique that mimics splinting. ${ }^{28}$ The splints are designed with a bamboo stick or palm leaf axis tied around the affected limb or body while using "old" cloth or cotton wood as stockinette. ${ }^{30}$ These splint often last for several months, and when removed, the patients only receives "vigorous" message with herbs and some incantations but no muscle strengthening program. ${ }^{27-31}$ The inability of the traditional bone setters to provide treatments which incorporates, for example, muscle strengthening and gait training, could be the main reason for subsequent falls, as their muscles are probably weak from disuse. Therefore, because traditional bone setters in Nigeria enjoy an enormous patronage amongst older adult population, there is a need to provide traditional bone setter practitioners with a form of education which includes knowledge of assessment and identification of weak muscles, training on progressive muscle strengthening exercises, prevention of joint stiffness and deformities, and gait re-education which if unaddressed, could predispose older adults to falls. ${ }^{27}$

Fall prevention practices including prescribing walking aids, exercises targeting muscle strengthening, balance training, educational advice, and environmental modification practices were identified by our participants. This is consistent with the literature. ${ }^{16,32,33}$ In as much as our participants identified the various fall prevention practices consistent with the literature, there was no evidence about the experience of preventing falls using a multifactorial approach to fall prevention. This finding seems 
troubling because a multifactorial approach to fall prevention is the most sustained approach that has reduced falls among older adults. ${ }^{34-37}$ However, our participants seem to have an understanding about collaboration with an occupational therapist on environmental modification as part of fall prevention practices. Therefore, it is possible that our participants have not experienced collaboration with any other healthcare professionals during fall prevention practices. Moreover, a multidisciplinary approach to practice seems to be an evolving culture among healthcare professionals in developing countries. ${ }^{38}$

There are several implications of this finding. First, educating healthcare professionals including physiotherapists on "why, when and how" to collaborate with other healthcare professionals during fall prevention interventions could be promising. Second, strategies to encourage a multidisciplinary approach to learning is crucial during the entry-level training of healthcare professionals. These two strategies might not be the best approach to changing practice, but could be a starting point in most developing nations. Surprisingly, our participants failed to specifically identify interventions that would target the fear of falling. This is troubling because the participants are experienced therapists in fall prevention and are expected to understand the holistic approach to fall prevention, not only focusing on interventions that target physical determinant of falls such as muscle strength, but also on the psycho-social determinants of falls such as fear of falling, social networking, and socio-economic factors. It is believed that practitioners using fall prevention guidelines often follow the holistic approach to fall prevention care. ${ }^{2}$ Therefore, it is possible that for a holistic approach to fall prevention in Nigeria, therapists should be encouraged to use fall prevention guideline in their practice.

Furthermore, barriers to practicing fall prevention among older adults were identified by our participants, and these barriers have been identified in the literature as well.8,39,40 Our participants expressed concerns about the inability of the patient's relative to follow fall prevention home-practice/education. However, there are possible reasons that could explain this phenomenon. First, there may be a communication issue in prescribing home exercises or explaining risk for falling to the older adults or relatives. Evidence shows that therapists working to complete their daily case load often do not have enough time to clearly explain exercises and other risk factors for falls to the older adults or their relatives.8,41 The high case load of the Nigerian therapists in addition to the patients' utmost trust in them often result in the therapist imposing advice/instructions to the patient's relatives without seeking the patient's/relative's opinion. ${ }^{42}$ This might seem troubling for healthcare professionals, especially therapists practicing in the developed countries, as their practice has advanced to the model of a patient-centered approach to care, where patients have a significant role in determining their care. However, because of cultural practices in some developing countries, seeking the opinion of a patient often times makes the him or her lose "faith" in the skills and qualification of the healthcare professional. Therefore, adopting the patient/family centered approach could be promising, but would require a great campaign of inter-professional educational series between/among the patients, the populace, and the healthcare professionals. Second, fall prevention home programs/education that involves finances would likely be ignored by the relatives, especially if there have been a financial constrict.

\section{Limitation and Recommendation}

While this might be the only study (published) that has explored the experiences of healthcare professionals in fall prevention in the sub-Saharan region of Africa, it is important we acknowledge the study's limitations. We interviewed only physiotherapist that are in Abuja- the capital city of Nigeria; therefore it is likely that their perception and experiences of fall prevention might be different from therapist practicing in the rural area. Because this study was explanatory and descriptive, we suggest that further study should explore fall prevention practices using a grounded theory approach with maximum variation sampling, which will enable the researcher to identify extreme cases and subsequently allow the researcher to assess whether patterns of experience differ or persist.

\section{CONCLUSION}

The experience of physiotherapists in fall prevention practices for older adults who are recurrent fallers includes identifying who are recurrent fallers, fall prevention practices, hindrances to fall prevention, and fall prevention practices as well as possible strategies. Our study added a contextual experience to fall prevention practice across the globe. The traditional bone setter's effect as a feature of older adults who are recurrent fallers was interesting. Exploring the communication pattern between physiotherapist in fall prevention practices and patients/relatives in more detail is warranted. 


\section{REFERENCES}

1. HelpAge. Global Age Watch Index 2015. [cited 25th August 2017]. Available from: http://www.helpage.org/global-age watch/population-ageing-data/country-ageing-data/?country=Nigeria.

2. National Institute for Health and Care Excellence (NICE). Falls in older people. NICE Quality Standard (QS86). UK, NICE Publications; 2015 [cited in 12th August, 2017]. Available from: http://www.nice.org.uk/guidance/qs68..

3. Tromp AM, Pluijm SM, Smit JH. Fall-risk screening test: A prospective study on predictors for falls in communitydwelling elderly. J Clin Epidemiol. 2001 Aug; 54(8): 837-844. [PMID: 11470394]

4. Tinetti ME, Deucette J, Claus E, Marottoli R. Risk factors for serious injury during falls by older persons in the community. J Am Geriatr Soc. 1995 Nov; 43(11): 1214-1221. [PMID: 7594154]

5. Deandrea S, Lucenteforte E, Bravi F, Foschi R, La Vecchia C, Negri E. Risk factors for falls in community-dwelling older people: "A systematic review and meta-analysis. Epidemiology. 2010 Sept; 21(5): 658-668. [PMID: 23294998]

6. World Health Organisation (WHO). Media Center: Facts Sheet on falls; 2015[cited in $8^{\text {th }}$ June 2018]. Available from: http://www.who int/mediacentre/factsheet/fs344/en.

7. Scott V, Wagar B, Sum A, Mercalfe S, Wagar L. Public health approach to fall prevention among older people in Canada. Clin Geriatr Med. 2010; 26: 705-718. doi:10.1016/j.cger.2010.06.003

8. Middlebrook S, Mackenzie L. The enhanced primary care program and falls prevention: Perceptions of private occupational therapist and physiotherapist. Australas J Ageing. 2012 Jun; 31(2): 72-77. DOI: 10.1111/j.17416612.2011.00527.x

9. National Council on the Aging. Falls free: Promoting a national falls prevention action plan. Washington, DC: The National Council on the Aging; 2004

10. Kalula, S. Prevention of falls in older persons; Africa Case study. A WHO Global report on Falls among older persons. South Africa: WHO publication; 2007 [cited in 16th May 2015] Available from: http://www.who.int/ageing/projects/AFRO.pdf.

11. Hale $L$, Taylor $D$, Waters $D$. Exercise is a proven fall prevention strategy: it should be embedded into usual physiotherapy practice. New Zea J Physiother. 2012 Jul; 40(2): 45-47.

12. Feder G, Cryer C, Donovan S, Carter Y. Guidelines for the prevention of falls in people over 65. BMJ. 2000 Oct; 321: 1007-1011. [PMCID: PMC1118778]

13. Peel C, Brown CJ, Lane A, Milliken E, Patel K. A survey of fall prevention knowledge and practice patterns in home health physical therapist. J Geriatr Phys Ther. 2008; 31(2): 64-70. doi: 10.1519/JPT.0b013e31822938ac

14. Brown $C$, Gottschalk M, Van Ness P, Fortimky H, Tinet H. Changes in physical therapy providers' use of fall prevention strategies following a multi-component behavioural change intervention. Phys Ther. 2005; 85(5): 394-403. PMID: 15842188

15. Stenberg $M$, Wann-Hansson $C$. Health care professionals' attitudes and compliance to clinical practice guidelines to prevent falls and fall injuries. Worldviews on Evid Based Nurs. 2011 Jun; 8(2): 87-95. [PMID:20663118]

16. Kalu ME, Vlachantoni A, Norman KE. Knowledge about risk factors for fall and practice about fall prevention in older adults among physiotherapist in Nigeria. Physiother Res Int. 2018; Imprint. doir.org/10.1002/pri.1742.

17. Nilsen P. Making sense of implementation theories, models and frameworks. Implement Sci. 2015 Apr; 10: 53. [PMID:25895742].

18. Sandelowski M. What's in a name? Qualitative description revisited. Res in Nurs Health. 2010 Feb 1;33(1):77-84. [PMID:20014004].

19. Creswell JW, Poth CN. Qualitative Inquiry \& research design: choosing among five approaches ( $4^{\text {th }}$ ed). Washingston DC: SAGE.

20. Braun, V. Clarke, V. Thematic analysis. In H. Cooper, P. M. Camic, D. L. Long, A. T. Panter, D. Rindskopf, \& K. J. Sher (Eds), APA handbook of research methods in psychology, Vol. 2: Research designs: Quantitative, qualitative, neuropsychological, and biological (pp. 57-71). Washington, DC: American Psychological Association; 2012.

21. Patto O. Qualitative Research and Evaluation Methods , 3 rd ed. California: SAGE Publication; 2002.

22. Caelli K. Engaging with phenomenology: is it more of a challenge than it needs to be? Qual Health Res. 2001 Mar; 11: 273-281. [PMID: 11221120].

23. Koch T, Harrington A. Reconceptualizing rigour: The case for reflexivity. J Adv Nurs. 1998 Oct; 28(4), 882-890. [PMID: 9829678].

24. Lincoln YS, Guba EG. Naturalistic inquiry. Beverly Hills, CA: Sage Publications; 1985.

25. Farombi TH, Owolabi MO, Ogunniyi A. Falls and their associated risks in Parkinson's disease patients in Nigeria. $J$ Mov Disord. 2016 Sept; 9(3): 160-165. PMID: 27667188

26. Gravesande J, Richardson J. Identifying non-pharmacological risk factors for falling in older adults with type 2 diabetes mellitus: a systematic review. Disabil Rehabil. 2017;Jul 39(15): 1459-1465. [ PMID: 27385376] 
27. Dada AA, Yinusa W, Giwa SO. Review of the practice of traditional bone setting in Nigeria. Afr Health Sci. 2011 Jun; 11(2): 262- 265. PMID: 21857859

28. Thanni LOA. Factors influencing patronage of traditional bonesetters. West Afri J Med. 2000 Jul-Sept; 19 (3): 220 224. [PMID: 11126089].

29. Abia RP, Okeke HC, Eyoma OE. Review of Traditional Bone Setting in Calabar Metropolis, Cross River State, Nigeria. Inter J Soc Sci. 2017 Jan;11(1).

30. Onuminya JE, Obekpa PO, Ihezue HC, Ukegbu ND, Onabowale BO. Major amputations in Nigeria: a plea to educate traditional bone setters. Trop Doct. 2000 Jul; 30(3): 133-135. [PMID: 10902466].

31. Onuminya JE. The role of the traditional bone setter in Primary fracture care in Nigeria. S. Afr Med J. 2004 Aug; 94(80):652-8. [PMID:15352590].

32. El-khourly F, Cassou BM, Latouche A, Aegerter P, Charles MA, Dargent-Molina F. Effectiveness of two year balance training programme on prevention of fall induced injuries in at risk women aged 75-85 living in community: Ossebo randomized controlled trial. BMJ. 2015 Jul; 351: h3830. [PMID: 26201510]

33. Cameron D, Gillespie D, Robertson M, Murray R, Hill D, Cumning G, Kerse N. Intervention for preventing falls in older people in care facilities and hospitals. Cochrane Database Syst Rev. 2012 Dec; 12: CD005465.pubs3 Review. [PMID: 23235623].

34. Costello E, Edelstein JE. Update on fall prevention for community-dwelling older adults: review of single and multifactorial intervention programs. J Rehabili Res Dev. 2008; 45(8): 1135-1152. [PMID:19235116].

35. Markle-Reid M, Browne G, Gafni A, Roberts J, Weir R, Thabane L, et al. The effects and costs of a multifactorial and interdisciplinary team approach to falls prevention for older home care clients 'at risk' for falling: a randomized controlled trial. Can J Aging. 2010 Mar; 29(1): 139-161. [PMID: 20202271].

36. Cumming RG, Sherrington C, Lord SR, Simpson JM, Vogler C, Cameron ID, et al. Cluster randomized trial of a targeted multifactorial intervention to prevent falls among older people in hospital. BMJ. 2008 Apr; 336(7647): 758-760. [PMID: 18332052]

37. Amacher AE, Nast I, Zindel B, Schmid L, Krafft V, Niedermann K. Exercise of general practitioners, home care nurses, physiotherapist and seniors involved in a multidisciplinary home-based fall prevention programme: A mixed method study. BMC Hea Serv Res. 2016; 16(1): 469. [PMID: 27595748]

38. Maher D, Smeeth L, Sekajugo J. La transición sanitaria en África: propuestas de normas prácticas para la atención primaria. Bull Wor Hea Organisat. 2010; 88(12): 943-948. [PMID: 21124720]

39. Welcome MO. The Nigeria healthcare system: Need for integrating adequate medical intelligence and surveillance systems. J Pharm Bio Sci. 2011; 3(4): 470-478. DOl: 10.4103/0975-7406.90100

40. Young DL, Moonie S, Bungum T. Cross-sectional examination of patient and therapist factors affecting participation in physical therapy in acute care hospital settings. Phys Thera. 2017 Jan; 97(1): 3-12. [PMID:27340196].

41. Chou WC, Tinetti ME, King MB, Irwin K, Fortinsky RH. Perceptions of physicians on the barriers and facilitators to integrating fall risk evaluation and management into practice. J Gen Intern Med. 2006 Feb 1;21(2):117-22. [PMID: 16336618].

42. Igwesi-Chidobe $\mathrm{C}$. Obstacles to obtaining optimal physiotherapy services in a rural community in southeastern Nigeria. Rehabil Res Pract. 2012; 2012:909675. [PMID: 22973517]. 